\title{
Genetic and environmental factors on heart rate, mean arterial pressure and carotid intima-media thickness: A longitudinal twin study
}

\author{
Adam D. Tarnoki ${ }^{1,2 *}$, Laszlo Szalontai $^{1 *}$, Corrado Fagnani ${ }^{3 *}$, David L. Tarnoki ${ }^{1,2}$,
} Pierleone Lucatelli ${ }^{4}$, Pal Maurovich-Horvat ${ }^{5}$, Adam L. Jermendy ${ }^{5}$, Attila Kovacs ${ }^{5}$, Andrea Agnes Molnar ${ }^{5}$, Erika Godor ${ }^{1}$, Bence Fejer $^{1}$, Anita Hernyes ${ }^{1}$, Carlo Cirelli ${ }^{4}$, Fabrizio Fanelli ${ }^{4}$, Filippo Farina ${ }^{6}$, Claudio Baracchini ${ }^{6}$, Giorgio Meneghetti, Anna V. Gyarmathy ${ }^{7}$, Gyorgy Jermendy ${ }^{8}$, Bela Merkely ${ }^{5}$, Giacomo Pucci ${ }^{9}{ }^{10}$, Giuseppe Schillaci ${ }^{9}$, Maria A. Stazi ${ }^{3}$, Emanuela Medda ${ }^{3}$

${ }^{1}$ Medical Imaging Center, Semmelweis University, Budapest, Hungary; ${ }^{2}$ Hungarian Twin Registry, Budapest, Hungary; ${ }^{3}$ Italian Twin Registry, Center for Behavioural Sciences and Mental Health, Istituto Superiore di Sanità, Rome, Italy; ${ }^{4}$ Vascular and Interventional Radiology Unit, Department of Radiological, Oncological and Anatomo-Pathological Sciences, Sapienza University of Rome, Italy;

${ }^{5}$ MTA-SE Cardiovascular Imaging Research Group, Heart and Vascular Center,

Semmelweis University, Budapest, Hungary; ${ }^{6}$ Department of Neurosciences, University of Padua School of Medicine, Padua, Italy; ${ }^{7}$ Johns Hopkins Bloomberg School of Public Health, Baltimore, MD, USA;

${ }^{8}$ Third Department of Internal Medicine, Bajcsy Zsilinszky Hospital, Budapest, Hungary;

${ }^{9}$ Università di Perugia, Unità di Medicina Interna, Ospedale "S. Maria”, Terni, Italy;

${ }^{10}$ Struttura Complessa di Medicina Interna, Azienda Ospedaliero-Universitaria di Terni, Italy

\begin{abstract}
Background: Heart rate (HR), mean arterial pressure (MAP) and carotid intima-media thickness (cIMT) are moderately heritable cardiovascular traits, but the environmental effects on the longitudinal change of their heritability have never been investigated.

Methods: 368 Italian and Hungarian twins (107 monozygotic, 77 dizygotic) underwent oscillometric measurement and B-mode sonography of bilateral carotid arteries in 2009/2010 and 2014. Within-individual/cross-study wave, cross-twin/within-study wave and cross-twin/cross-study wave correlations were estimated, and bivariate Cholesky models were fitted to decompose the total variance at each wave and covariance between study waves into additive genetic, shared and unique environmental components. Results: For each trait, a moderate longitudinal stability was observed, with within-individual/crosswave correlations of 0.42 (95\% CI: 0.33-0.51) for HR, 0.34 (95\% CI: 0.24-0.43) for MAP, and 0.23 (95\% CI: 0.12-0.33) for cIMT. Cross-twin/cross-wave correlations in monozygotic pairs were all significant and substantially higher than the corresponding dizygotic correlations. Genetic continuity was the main source of longitudinal stability, with across-time genetic correlations of 0.52 (95\% CI: 0.29-0.71) for HR, 0.56 (95\% CI: 0.31-0.81) for MAP, and 0.36 (95\% CI: 0.07-0.64) for cIMT. Overlapping genetic factors explained respectively $57 \%, 77 \%$, and $68 \%$ of the longitudinal covariance of the HR, MAP and cIMT traits. Conclusions: Genetic factors have a substantial role in the longitudinal change of HR, MAP and cIMT; however, the influence of unique environmental factors remains relevant. Further studies should better elucidate whether epigenetic mechanisms have a role in influencing the stability of the investigated traits over time. (Cardiol J 2021; 28, 3: 431-438)
\end{abstract}

Key words: cardiovascular arterial stiffness, epigenetics, genetics

Address for correspondence: Laszlo Szalontai, MD, Medical Imaging Center, Semmelweis University, 78/A Ulloi street, Budapest 1082, Hungary, tel: +36-30-6401183, fax: +36-1-2780368, e-mail: laszlo.szalontai.med@gmail.com

*These authors contributed equally to this work; ${ }^{\dagger}$ This author passed away during manuscript preparation.

This article is available in open access under Creative Common Attribution-Non-Commercial-No Derivatives 4.0 International (CC BY-NC-ND 4.0) license, allowing to download articles and share them with others as long as they credit the authors and the publisher, but without permission to change them in any way or use them commercially. 


\section{Introduction}

Each year, cardiovascular disease (CVD) causes 3.9 million deaths, accounting for almost half of all deaths in Europe [1].

Some of the most commonly used non-invasive methods to assess CVD risk include cardiovascular measures such as heart rate (HR), mean arterial pressure (MAP), and carotid intima-media thickness (cIMT). A considerable number of epidemiological studies have reported a strong association between elevated HR and cardiovascular risk, and this association appears to be independent of other major risk factors for atherosclerosis [2]. These studies suggest that HR does not merely predict outcome, but that elevated heart rate may be a true cardiovascular risk factor [3].

Mean arterial pressure is a steady component of the blood pressure (BP) curve. The two main determining factors of MAP are cardiac output and peripheral vascular resistance, which are regulated by a network of interacting physiological pathways involving extracellular fluid volume homeostasis, cardiac contractility and vascular tone through renal, neural and endocrine systems [4]. cIMT is a marker of subclinical atherosclerosis normally increasing with age and generally related to the male gender. Approximately $20 \%$ to $30 \%$ of cerebral strokes are thought to be the result of ischemia from extracranial carotid stenosis due to atherosclerosis [5]. While HR, $\mathrm{BP}$, and cIMT have been linked to environmental factors, cross-sectional twin and family studies have also shown a strong genetic component [6-12]. However, being complex traits, environmental factors are likely to play an important role in the longitudinal modification of the genetic influence but, the timespan over which these changes take effect is unclear $[13,14]$.

The environmental effects on the longitudinal change of HR, MAP and cIMT heritability have never been investigated. Significant changes in associations with genetic components over a considerably long timespan (for example, 5 years) would suggest higher importance of gene environment interaction. The aim of this longitudinal twin study was to investigate genetic and environmental influences on the stability of HR, MAP, and cIMT as CVD defining traits to provide an insight into whether environmental interventions might have a substantial beneficial effect.

\section{Methods}

\section{Patients}

In 2009/2010, 662 twins previously enrolled in the Italian and Hungarian Twin Registries were recruited in the "International twin study on atherosclerotic traits" (Wave 1) [8]. Of these, 368 participated in a second study wave (2014), with 294 (44.4\%) not participating in the followup investigation. Attrition is explained in part by death of participants after Wave 1 , health reasons, loss to follow-up due to a change of address, and the fact that only complete twin pairs could be enrolled in the study. All patients were Caucasian ethnicity. No significant differences in zygosity as well as in several baseline characteristics (such as educational level, systolic BP (SBP) and diastolic $\mathrm{BP}$ (DBP), smoking habits, diabetes, hypertension and cardiac disease and MAP) were found between those who took part in Wave 2 and those who were not followed up. However, participants who were followed up were significantly older, drank more coffee or alcohol, had higher body mass index (BMI) and showed lower HR at baseline compared to those who were not followed up. The Italian twins were residents of Rome, Padua, Perugia or Terni, while Hungarian twins lived in Budapest or in the province. Exclusion criteria at both visits were being pregnant at the time of the visit, prior CVDs or surgeries that might interfere with the investigated phenotypes, and acute infection occurring 2 weeks prior to their visit. Twins were examined, and data were collected at the local university hospitals. All participants signed an informed consent form in acceptance of entering the study. This observational study was approved by the Ethics Committee of the Istituto Superiore di Sanità as part of the Italian Twin Registry research activities, and the study was performed in accordance with the declaration of Helsinki.

\section{Ethics approval and consent to participate}

The study was approved by the Ethics Committee Semmelweis University TUKEB 29/2009, and the committee's reference number is ETT TUKEB 58401/2012/EKU (828/PI/12).

\section{Data collection and measures}

Heart rate, MAP, systolic aortic BP (SBPao), cIMT, and BMI were recorded by oscillometric measurement, B-mode sonography of bilateral carotid arteries and bioelectrical impedance analysis (OMRON) in 2009 and in 2014, using the same devices. Prior to measurements, participants were requested to refrain from smoking for at least $3 \mathrm{~h}$, from eating for at least $1 \mathrm{~h}$, and from drinking alcohol or coffee for at least $12 \mathrm{~h}$. Subjects were asked not to speak during the measurements. The HR and MAP measurements were obtained after at least 
10 min of resting in supine position using a previously validated [15], brachial cuff-based oscillometric device (Tensiomed Arteriograph, Medexpert Ltd., Budapest, Hungary). Mean arterial pressure was calculated as DBP + 1/3 (SBP - DBP). B-mode ultrasound was performed using high-resolution color-coded duplex sonography scanners (Esaote MyLab70 in Rome, Italy; Sonoscape S8 in Perugia, Italy; Toshiba Aplio XG in Padua, Italy; Esaote MyLab60 in Terni, Italy; Philips iU22 in Hungary) with high-frequency $(12 \mathrm{MHz})$ linear probes. Carotid arteries were examined by the same reader bilaterally from the supraclavicular fossa to the submandibular angle, including common carotid artery (CCA), carotid bulb, and origin of both internal and external carotid arteries (ICA and ECA). Intima-media thickness was defined according to the Mannheim consensus [16]. IMT was measured 2 to $3 \mathrm{~cm}$ before the carotid bifurcation on the far wall. In cases of the presence of a carotid plaque, an area nearby without plaque was measured. Afterwards, cIMT was measured by semiautomated software online or offline in the saved images, or by calipers. Information on risk factors, chronic diseases, medications, and any other clinically relevant condition were collected by self-reported questionnaires. Twin zygosity was assessed by a self-reported questionnaire, filled out by each twin, regarding physical differences and similarities during childhood [17, 18].

\section{Statistical analysis}

Descriptive statistics (percentage distributions and mean values with their corresponding standard deviations) were produced for the overall sample and by zygosity at Wave 1 and Wave 2 . Since monozygotic (MZ) twins are genetically identical and dizygotic (DZ) twins who share, on average, $50 \%$ of the genes, and both $\mathrm{MZ}$ and $\mathrm{DZ}$ twins are exposed to the same environment especially during childhood, a higher correlation of the examined traits in $\mathrm{MZ}$ than in $\mathrm{DZ}$ pairs suggests a contribution of genetic factors to the trait expression. The role of genetic and environmental factors in the expression of each trait was inferred by a comparison of "crosstwin/within-wave" correlations (i.e. between twin 1 and twin 2 at a given wave) between $\mathrm{MZ}$ and $\mathrm{DZ}$ pairs. Longitudinal phenotypic correlation ("within-individual/cross-wave" correlation, i.e. between Wave 1 and Wave 2 for twins as individuals) was calculated to investigate the stability of each trait over time. "Cross-twin/cross-wave" correlation (i.e. between twin 1 at a given wave and twin 2 at a different wave) was calculated in order to assess the stability of genetic and environmental effects across the two visits; greater values of such correlation for $\mathrm{MZ}$ compared to $\mathrm{DZ}$ pairs are interpreted as a genetic stability between Wave 1 and Wave 2. Bivariate Cholesky decomposition was performed for each trait to estimate genetic and environmental contributions to the variance at each wave and to the covariance between waves under the full and best model. The $\chi^{2}$ test was used to select the best fitting model according to parsimonious criteria [19]. The contribution to variance and covariance can be decomposed in three main effects: (i) additive genetic component (A), due to additive effects of alleles at each contributing genetic locus; (ii) shared environmental component (C), attributable to environmental events common to both members of a twin pair; (iii) unique environmental component (E), which results from environmental exposures not shared by members of a twin pair, including measurement errors. Genetic and environmental variance and covariance components were expressed as percentages of the total observed variance/covariance. Therefore, the standardized genetic variance component, called heritability, was defined as the proportion of variance of a single trait (at a given wave) attributable to genetic influences. Furthermore, the standardized genetic covariance, called bivariate heritability, was defined as the proportion of phenotypic correlation (between waves) explained by common genetic influences at Wave 1 and Wave 2 . Finally, genetic and environmental correlations were estimated to assess the extent to which the same genes and environments affected the traits across visits. All estimated parameters were adjusted by age, gender, country, BMI at baseline and, when necessary, by SBPao at baseline based on the Framingham Heart Study [20]. Descriptive statistics were obtained using the STATA Software, release 13. In addition, correlation estimation and bivariate Cholesky decomposition were performed using the Mx software [21].

\section{Results}

A total of $214 \mathrm{MZ}$ twins and $154 \mathrm{DZ}$ twins were included in the analysis (Table 1): $59.8 \%$ of the sample was recruited in Italy and about one-third of the twins were male (34.8\%). The mean age at first visit was 51.9 years (range 19-73). No significant differences between zygosity groups for HR, MAP and cIMT were found. Within-pair similarity in $\mathrm{MZ}$ twin pairs was greater than that observed in $\mathrm{DZ}$ pairs for all the traits (Table 2). Phenotypic 
Table 1. Demographic, clinical characteristics and measures by zygosity and time.

\begin{tabular}{|c|c|c|c|c|}
\hline & \multicolumn{2}{|c|}{ Monozygotic twins } & \multicolumn{2}{|c|}{ Dizygotic twins } \\
\hline & Wave $1(2009 / 10)$ & Wave 2 (2014) & Wave $1(2009 / 10)$ & Wave 2 (2014) \\
\hline Subjects, number & 214 & 214 & 154 & 154 \\
\hline Age [years] & $51.45 \pm 13.25$ & $56.11 \pm 13.40$ & $52.45 \pm 12.19$ & $57.12 \pm 12.26$ \\
\hline Gender, male & $35.5 \%$ & - & $33.8 \%$ & - \\
\hline \multicolumn{5}{|l|}{ Country: } \\
\hline Hungary & $46.7 \%$ & - & $31.2 \%$ & - \\
\hline Italy & $53.3 \%$ & - & $68.8 \%$ & - \\
\hline \multicolumn{5}{|l|}{ Smoke: } \\
\hline Never smoker & $59.7 \%$ & $59.5 \%$ & $50.0 \%$ & $48.3 \%$ \\
\hline $\begin{array}{l}\text { Former smoker - Current } \\
\text { smoker }\end{array}$ & $40.3 \%$ & $40.5 \%$ & $50.0 \%$ & $51.7 \%$ \\
\hline Body mass index $\left[\mathrm{kg} / \mathrm{m}^{2}\right]$ & $26.20 \pm 4.45$ & $26.55 \pm 4.50$ & $26.86 \pm 4.59$ & $27.06 \pm 4.86$ \\
\hline Heart rate & $69.91 \pm 11.27$ & $67.14 \pm 9.80$ & $69.27 \pm 9.66$ & $65.25 \pm 8.77$ \\
\hline $\begin{array}{l}\text { Mean arterial pressure } \\
{[\mathrm{mmHg}]}\end{array}$ & $94.24 \pm 12.53$ & $93.12 \pm 11.48$ & $92.97 \pm 12.20$ & $93.50 \pm 13.05$ \\
\hline $\begin{array}{l}\text { Carotid intima-media } \\
\text { thickness [mm] }\end{array}$ & $0.71 \pm 0.25$ & $0.69 \pm 0.19$ & $0.71 \pm 0.20$ & $0.74 \pm 0.22$ \\
\hline Hyperlipidemia & $71.1 \%$ & $65.2 \%$ & $69.5 \%$ & $66.2 \%$ \\
\hline $\begin{array}{l}\text { Brachial systolic blood } \\
\text { pressure }[\mathrm{mmHg}]\end{array}$ & $128.58 \pm 17.26$ & $126.39 \pm 16.68$ & $127.13 \pm 16.63$ & $126.66 \pm 17.35$ \\
\hline $\begin{array}{l}\text { Brachial diastolic blood } \\
\text { pressure }[\mathrm{mmHg}]\end{array}$ & $77.01 \pm 11.29$ & $76.52 \pm 9.96$ & $76.44 \pm 9.99$ & $76.82 \pm 11.81$ \\
\hline
\end{tabular}

Data are expressed as mean \pm standard deviation or percentage (\%).

Table 2. Intraclass and cross-twin/cross-time correlations by zygosity.

\begin{tabular}{|c|c|c|c|c|}
\hline & & \multirow{2}{*}{$\begin{array}{c}\text { Phenotypic } \\
\text { correlation } \\
(95 \% \mathrm{Cl})\end{array}$} & \multicolumn{2}{|c|}{ Correlations (95\% CI) } \\
\hline & & & Monozygotic & Dizygotic \\
\hline \multicolumn{5}{|l|}{ HR $^{*}$} \\
\hline Visit 1-Visit 2 & Within-individual/cross-time correlation & $0.42(0.33-0.51)$ & & \\
\hline Visit 1 & Cross-twin/within-time correlation & & $0.47(0.33-0.59)$ & $0.27(-0.02-0.49)$ \\
\hline Visit 2 & Cross-twin/within-time correlation & & $0.44(0.28-0.57)$ & $0.30(0.06-0.50)$ \\
\hline Visit 1-Visit 2 & Cross-twin/cross-time correlation & & $0.24(0.11-0.35)$ & $0.16(-0.05-0.33)$ \\
\hline \multicolumn{5}{|l|}{ MAP* } \\
\hline Visit 1-Visit 2 & Within-individual/cross-time correlation & $0.34(0.24-0.43)$ & & \\
\hline Visit 1 & Cross-twin/within-time correlation & & $0.44(0.27-0.57)$ & $0.37(0.17-0.54)$ \\
\hline Visit 2 & Cross-twin/within-time correlation & & $0.50(0.33-0.64)$ & $0.10(-0.10-0.28)$ \\
\hline Visit 1-Visit 2 & Cross-twin/cross-time correlation & & $0.27(0.14-0.39)$ & $0.11(-0.05-0.26)$ \\
\hline \multicolumn{5}{|l|}{ CCA IMT** } \\
\hline Visit 1-Visit 2 & Within-individual/cross-time correlation & $0.23(0.12-0.33)$ & & \\
\hline Visit 1 & Cross-twin/within-time correlation & & $0.32(0.23-0.46)$ & $0.13(-0.01-0.37)$ \\
\hline Visit 2 & Cross-twin/within-time correlation & & $0.59(0.48-0.65)$ & $0.24(0.04-0.42)$ \\
\hline Visit 1-Visit 2 & Cross-twin/cross-time correlation & & $0.15(0.02-0.27)$ & $0.09(-0.09-0.17)$ \\
\hline
\end{tabular}

HR — heart rate; MAP - mean arterial pressure; CCA — common carotid artery; IMT — intima-media thickness; SBPao - aortic systolic blood pressure; $\mathrm{BMI}$ - body mass index; ${ }^{*}$ Covariates included in the model: age, gender, country, body mass index; ${ }^{* *}$ Covariates included in the model: age, gender, country, SBPao, body mass index; $95 \% \mathrm{Cl}-95 \%$ confidence intervals 
correlations between the first and second visits for HR, MAP and cIMT were $0.42,0.34$, and 0.23 , respectively. Cross-twin/cross-wave correlations were higher in $\mathrm{MZ}$ twin pairs (range 0.15-0.27) than in DZ pairs (range 0.09-0.16). The highest difference between $\mathrm{MZ}$ and $\mathrm{DZ}$ twin correlations was observed for MAP (MZ: 0.27 and DZ: 0.11). Under the best model (AE), the variability of $\mathrm{HR}$ and MAP at first and second visits was explained, in similar proportions, by genetic (A from 0.48 to 0.45 ) and unique environmental influences ( $\mathrm{E}$ from 0.52 to 0.55 ; Table 3 ). Unique environmental influences on cIMT expression decreased between the first visit $(\mathrm{E}=0.68)$ and the second visit $(\mathrm{E}=0.42)$, whereas genetic effects increased from 0.32 to 0.58 between the two visits. For longitudinal changes in HR, proportions of covariance were explained by genetic and environmental influences were $\mathrm{A}=0.57$ and $\mathrm{E}=0.43$, respectively. Genetic factors involved in MAP and cIMT expression accounted for, respectively, $77 \%$ and $68 \%$ of the longitudinal covariance of the traits; the contribution of nonshared exposures to the stability of the traits over time was quite modest ( $\mathrm{E}=0.23$ and 0.32 ). Familial environmental influences did not contribute significantly to the longitudinal stability and change of HR, MAP and cIMT; indeed, the exclusion of $\mathrm{C}$ component had no effect in the model fit of any of the three phenotypes ( $p>0.05)$. Many of the same genes were involved in the expression of the observed traits over time (genetic correlation, rg: $\mathrm{HR}=0.52, \mathrm{MAP}=0.56$ and $\mathrm{cIMT}=0.36$ ), while different unique environmental factors acted across visits (environmental correlation, re: $\mathrm{HR}=$ $=0.34$, $\mathrm{MAP}=0.15$ and $\mathrm{cIMT}=0.14$ ).

\section{Discussion}

In this study, substantial influences of genetic background on phenotypic correlations of all studied phenotypes were revealed over time. Moreover, data herein, highlighted that shared, primarily familial, environmental influences do not contribute significantly to the longitudinal stability and change of HR, MAP, and cIMT.

\section{Heart rate}

Stress and depression are among the main factors raising HR [22]. Environmental factors associated with higher HR can be divided in two groups. The first one includes lifestyle choices such as alcohol consumption [23], smoking [24], absence of exercise, and higher BMI [25]. The second one refers to occupation related exposure

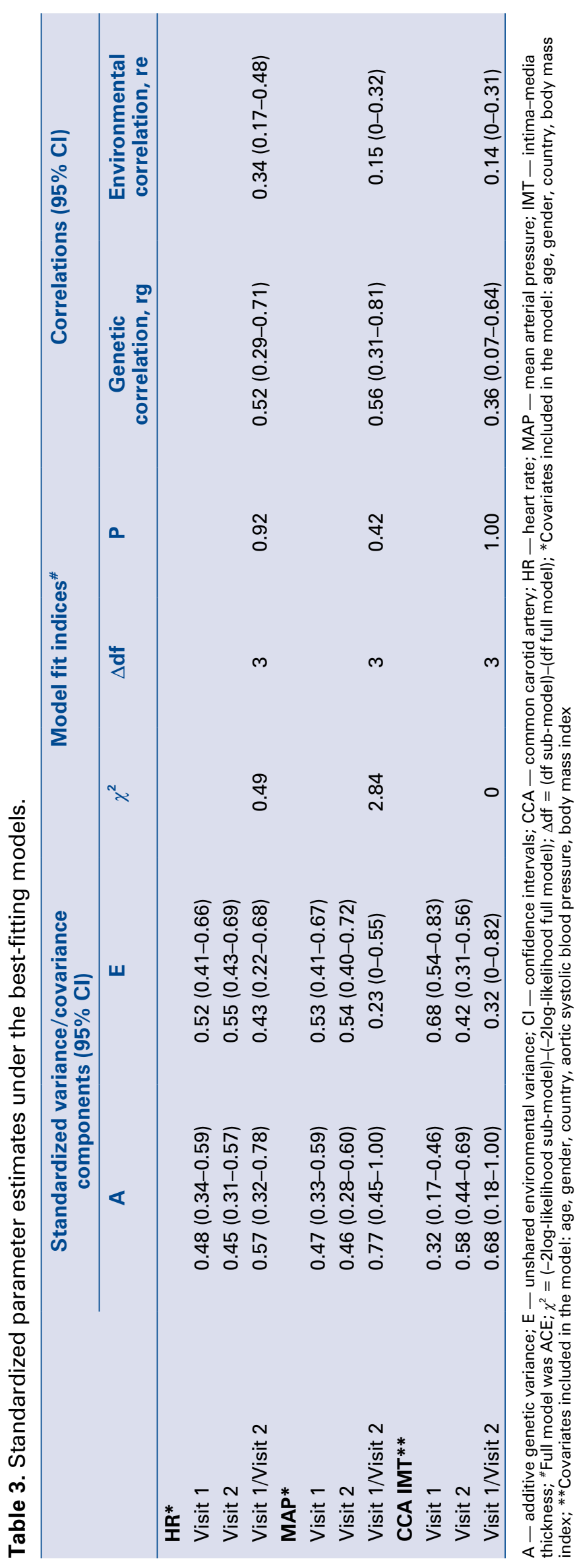


such as exposure to particulate matter, several chemical components, electromagnetic fields, vibrating tools, psychosocial stress, long working hours, and fatigue [26]. A large body of evidence ranging from epidemiologic to genome-wide linkage studies, suggests that in addition to the effect of environmental factors on HR, some features of $\mathrm{HR}$ and $\mathrm{HR}$ variability (HRV) can be transmitted over generations because of the influence of genetic factors. The Framingham Heart Study in 2002 and the Examination of the "unified database for human genome mapping" provided evidence for distinct HRV quantitative trait loci on chromosomes 15 and 2 [27]. There were interesting candidate genes related to the autonomic nervous system and HRV around the region of interest on chromosome 2 [27]. A recent GWAS cohort by Eppinga et al. [28] identified 46 novel loci associated with resting HR and hypothesized that either the genetic variants exerted their effects via $H R$ on mortality directly, or the genetic variants shared an underlying biology, both increasing HR and mortality risk. The present study provided further evidence on the role of genetic influence on HR by finding that the overall effect of the known environmental factors accounted for $52 \%$ to $55 \%$ of the variance. This is in accordance with a previous Danish study that demonstrated lower heritability (23\% to 27\%) while adjusting for age, gender, BMI, diabetes, hypertension, pulmonary function, smoking, physical activity and zygosity [6]. The current study also indicated that these known genetic and environmental factors had a modest but stable effect over time. Phenotypic correlation between the first and second visits for HR showed a moderate stability of the trait across time. This may suggest that environment played a non-significant effect on genetic expression through gene-environment interaction over a 5 -year period.

\section{Mean arterial pressure}

Factors that increase MAP include high BMI, age, short sleep time and/or sleep apnea syndrome, high sodium intake, smoking [29, 30], stress, and clinically related diseases such as diabetes and chronic kidney disease [31]. Studies have shown that environmental influences explain $30-50 \%$ of the variance in MAP [32, 33]. Cultural heritability, comprising a constellation of factors such as lifestyle and dietary habits, might explain an additional 10\% [32, 33]. A 2016 study showed that the majority of patients diagnosed with hypertension had high dietary sodium intake and low physical activity with high BMI and abdominal obesity [34].
Furthermore, a study by Małyszko et al. [35] found high prevalence and profound vitamin D deficiency in heart failure patients. Genetic heritability is estimated to account for about $40 \%$ of BP variance (ranging from $31 \%$ to $68 \%$, depending on the study) [32, 33]. Some residual proportion of variance (estimated at about $10 \%$ ) remains unknown. However, the genetic determinants are probably highly heterogeneous, which poses exceptional challenges to identification of the underlying genes. Burello et al. [36] described 43 single-nucleotide polymorphisms (SNP) variants, in a recent GWAS study, with each SNP affecting SBP and DBP by 1.0 and $0.5 \mathrm{mmHg}$, respectively. In 2017 one of the largest GWAS research studies to this date, that used the 1000 Genomes Project-based imputation in 150,134 European ancestry individuals reported 8 loci of the genome not previously connected to $\mathrm{BP}$ regulation and increasing the number of genes to 48 as candidates for priority follow-up [37]. Epigenetic changes, such as DNA methylation, histone modification and non-coding RNAs, have been increasingly recognized as important players in BP regulation and may justify a further part of missing heritability [36]. However, to this end, the longitudinal role of these effects on BP heritability remained unclear. In recent twin studies, MAP heritability ranged between $46 \%$ and $47 \%$, which is in line with the magnitude of the previous heritability results of BP traits [8]. Based on the phenotypic correlation between the two study waves, the present study found a low to moderate longitudinal stability of MAP, with cross-twin/ /cross-wave correlations giving a first indication of genetic and environmental influences on the detected stability. In the current study, the higher correlation observed in $\mathrm{MZ}$ twin pairs compared to $\mathrm{DZ}$ pairs suggests that genes mainly contribute to the stability of the trait over time.

\section{Carotid IMT}

Age and BMI are the most influential environmental factors on cIMT increase, followed by pulse pressure, gender (higher cIMT values in men, although gender difference is partly attributable to differences in carotid lumen diameter), waist-hip ratio, total cholesterol, low-density lipoprotein cholesterol, triglycerides, number of pack-years of smoking, and lumen diameter of the carotid artery [38]. The ARYA Study showed a linear trend with increased cIMT after adjusting the total pack-years of smoking for age and gender [38]. cIMT increases gradually and significantly with the number of cardiovascular risk factors mentioned above. In contrast, high-density 
lipoprotein cholesterol level is inversely associated with cIMT [39]. The Italian working group previously showed a genetic contribution ranging from $41 \%$ to $65 \%$ across the different carotid segments [9]. In a recent study Cecelja et al. [40] no association was found between longitudinal progression (5 years) of carotid artery pulse pressure and cIMT or carotid dilation and cIMT. This suggests that both pulse pressure and dilation are heritable but independent of IMT. Based on the present results, phenotypic correlation between the two waves suggests a moderate, significant longitudinal stability of cIMT. Moreover, the current data highlighted that shared environment (primarily familial exposures shared by both twins, such as dietary habits in childhood, parental socioeconomic status, etc.) did not contribute significantly to the longitudinal stability and change of cIMT, while unique environment had a substantial influence.

\section{Limitations of the study}

The present study has two limitations. First, the study was carried out in samples from different countries with different prevalence of hypertension, hypercholesterolemia, genetic background and other risk factors. However, this allowed us to study a more diverse sample. Second, preventive interventions or treatments might have affected the findings. However, conducting a sensitivity analysis excluding twins that changed treatment profile (i.e. not treated at baseline and treated at second wave or vice versa), the results were similar, suggesting that treatment likely had a negligible effect on the genetic component.

\section{Conclusions}

The current study of a relatively large twin cohort had the strength of being conducted by the same researchers and devices in all subjects in both study waves, using a standardized measurement procedure. This study revealed substantial influences of genetic background on longitudinal stability of all studied phenotypes over time. Moreover, data herein highlighted that shared, primarily familial, environmental influences do not contribute significantly to longitudinal stability and change of HR, MAP and cIMT. The present findings suggest that unique environmental, epigenetic changes may have a lower but considerable role in the expression of these CVD defining traits over a 5 -year period due to genetic stability.

Funding: Balassi Institute, Hungarian Scholarship Office and Italian Cultural Institute, Medexpert
Ltd., Semmelweis University Directorate of International Relations and University of Padua, EFSD New Horizons Programme. The position of Giacomo Pucci as an Adjunct Assistant Professor at the University of Perugia was funded by a grant from the Fondazione Cassa di Risparmio di Terni e Narni.

\section{Conflict of interest: None declared}

\section{References}

1. World Health Organization 2017. http://www.euro.who.int/en/ healthtopics/ noncommunicable-diseases/cardiovascular-diseases/data-and-statistics(Accessed on 15 October, 2017).

2. Perret-Guillaume C, Joly L, Benetos A. Heart rate as a risk factor for cardiovascular disease. Prog Cardiovasc Dis. 2009; 52(1): 6-10, doi: 10.1016/j.pcad.2009.05.003, indexed in Pubmed: 19615487.

3. Zheng L, Sun Z, Li J, et al. Pulse pressure and mean arterial pressure in relation to ischemic stroke among patients with uncontrolled hypertension in rural areas of China. Stroke. 2008; 39(7): 1932-1937, doi: 10.1161/STROKEAHA.107.510677, indexed in Pubmed: 18451345.

4. Mayet J, Hughes A. Cardiac and vascular pathophysiology in hypertension. Heart. 2003; 89(9): 1104-1109, doi: 10.1136/ heart.89.9.1104, indexed in Pubmed: 12923045.

5. Executive Committee for the Asymptomatic Carotid Atherosclerosis Study. Endarterectomy for asymptomatic carotid artery stenosis. JAMA. 1995; 273(18): 1421-1428, indexed in Pubmed: 7723155 .

6. Jensen MT, Wod M, Galatius S, et al. Heritability of resting heart rate and association with mortality in middle-aged and elderly twins. Heart. 2017; pii: heartjnl-2016-310986.

7. Osztovits J, Horváth T, Littvay L, et al. Effects of genetic vs. environmental factors on cardiovascular autonomic function: a twin study. Diabet Med. 2011; 28(10): 1241-1248, doi: 10.1111/j.14645491.2011.03363.x, indexed in Pubmed: 21679234.

8. Tarnoki AD, Tarnoki DL, Stazi MA, et al. Heritability of central blood pressure and arterial stiffness: a twin study. J Hypertens. 2012; 30(8): 1564-1571, doi: 10.1097/HJH.0b013e32835527ae, indexed in Pubmed: 22688268.

9. Medda E, Fagnani C, Schillaci G, et al. Heritability of arterial stiffness and carotid intima-media thickness: an Italian twin study. Nutr Metab Cardiovasc Dis. 2014; 24(5): 511-517, doi: 10.1016/j. numecd.2013.10.031, indexed in Pubmed: 24582685.

10. Zhao J, Cheema FA, Bremner JD, et al. Heritability of carotid intima-media thickness: a twin study. Atherosclerosis. 2008; 197(2): 814-820, doi: 10.1016/j.atherosclerosis.2007.07.030, indexed in Pubmed: 17825306.

11. Jermendy G, Littvay L, Steinbach R, et al. [Heritability of the risk factors characteristic for the metabolic syndrome: a twin study]. Orv Hetil. 2011; 152(32): 1265-1271, doi: 10.1556/ OH.2011.29165, indexed in Pubmed: 21803723.

12. Albarwani S, Muñoz ML, Voruganti VS, et al. Heritability of ambulatory and beat-to-beat office blood pressure in large multigenerational Arab pedigrees: the 'Oman Family study'. Twin Res Hum Genet. 2012; 15(6): 753-758, doi: 10.1017/thg.2012.59, indexed in Pubmed: 22967944.

13. Egger G, Liang G, Aparicio A, et al. Epigenetics in human disease and prospects for epigenetic therapy. Nature. 2004; 
429(6990): 457-463, doi: 10.1038/nature02625, indexed in Pubmed: 15164071.

14. Weinhold B. Epigenetics: the science of change. Environ Health Perspect. 2006; 114(3): A160-A167, doi: 10.1289/ehp.114-a160, indexed in Pubmed: 16507447.

15. Horváth IG, Németh A, Lenkey $Z$, et al. Invasive validation of a new oscillometric device (Arteriograph) for measuring augmentation index, central blood pressure and aortic pulse wave velocity. J Hypertens. 2010; 28(10): 2068-2075, doi: 10.1097/ HJH.0b013e32833c8a1a, indexed in Pubmed: 20651604.

16. Touboul PJ, Hennerici MG, Meairs S, et al. Mannheim carotid intima-media thickness consensus (2004-2006). An update on behalf of the Advisory Board of the 3rd and 4th Watching the Risk Symposium, 13th and 15th European Stroke Conferences, Mannheim, Germany, 2004, and Brussels, Belgium, 2006. Cerebrovasc Dis. 2007; 23(1): 75-80, doi: 10.1159/000097034, indexed in Pubmed: 17108679.

17. Kyvik KO, Green A, Beck-Nielsen H. The new Danish Twin Register: establishment and analysis of twinning rates. Int J Epidemiol. 1995; 24(3): 589-596, doi: 10.1093/ije/24.3.589, indexed in Pubmed: 7672901.

18. Heath AC, Nyholt DR, Neuman R, et al. Zygosity diagnosis in the absence of genotypic data: an approach using latent class analysis. Twin Res. 2003; 6(1): 22-26, indexed in Pubmed: 12626225.

19. Neale M, Cardon LR. Methodology for genetic studies of twins and families. Kluwer Academic Publishers, Dordrecht 1992.

20. Brown WM, Beck SR, Lange EM, et al. Framingham Heart Study. Age-stratified heritability estimation in the Framingham Heart Study families. BMC Genet. 2003; 4 Suppl 1: S32, doi: 10.1186/1471-2156-4-S1-S32, indexed in Pubmed: 14975100.

21. Neale MC, Boker SM, Xie G, et al. Mx: statistical modeling (7th edition), Ed. Richmond, VA: Department of Psychiatry, Virginia Commonwealth University. 2006.

22. Parati G, Mancia G, Rienzo M, et al. Cardiovascular variability is/ /is not an index of autonomic control of circulation. J App Physiol. 2006; 101(2): 690-691, doi: 10.1152/japplphysiol.00584.2006.

23. Albanese M, Neofytou M, Ouarrak T, et al. Evaluation of heart rate measurements in clinical studies: a prospective cohort study in patients with heart disease. Eur J Clin Pharmacol. 2016; 72(7): 789-795, doi: 10.1007/s00228-016-2046-9, indexed in Pubmed: 27023464

24. Filipovský J, Ducimetière P, Safar ME. Prognostic significance of exercise blood pressure and heart rate in middle-aged men. Hypertension. 1992; 20(3): 333-339, doi: 10.1161/01.hyp.20.3.333, indexed in Pubmed: 1387630.

25. Palatini P, Casiglia E, Pauletto P, et al. Relationship of tachycardia with high blood pressure and metabolic abnormalities: a study with mixture analysis in three populations. Hypertension. 1997; 30(5): 1267-1273, doi: 10.1161/01.hyp.30.5.1267, indexed in Pubmed: 9369286.

26. Moser M, Lehofer M, Sedminek A, et al. Heart rate variability as a prognostic tool in cardiology. A contribution to the problem from a theoretical point of view. Circulation. 1994; 90(2): 1078-1082, doi: 10.1161/01.cir.90.2.1078, indexed in Pubmed: 8044922 .

27. Palatini P, Thijs L, Staessen JA, et al. Systolic Hypertension in Europe (Syst-Eur) Trial Investigators. Predictive value of clinic and ambulatory heart rate for mortality in elderly subjects with systolic hypertension. Arch Intern Med. 2002; 162(20):
2313-2321, doi: 10.1001/archinte.162.20.2313, indexed in Pubmed: 12418945.

28. Eppinga RN, Hagemeijer Y, Burgess S, et al. Identification of genomic loci associated with resting heart rate and shared genetic predictors with all-cause mortality. Nat Genet. 2016; 48(12): 1557-1563, doi: 10.1038/ng.3708, indexed in Pubmed: 27798624.

29. Ma Y, He FJ, MacGregor GA. High salt intake: independent risk factor for obesity? Hypertension. 2015; 66(4): 843-849, doi: 10.1161/HYPERTENSIONAHA.115.05948, indexed in Pubmed: 26238447.

30. Phillips CL, O'Driscoll DM. Hypertension and obstructive sleep apnea. Nat Sci Sleep. 2013; 5: 43-52, doi: 10.2147/NSS.S34841, indexed in Pubmed: 23750107.

31. Cabrera CP, Ng FuL, Warren HR, et al. Exploring hypertension genome-wide association studies findings and impact on pathophysiology, pathways, and pharmacogenetics. Wiley Interdiscip Rev Syst Biol Med. 2015; 7(2): 73-90, doi: 10.1002/wsbm.1290, indexed in Pubmed: 25655479.

32. Rossi GP, Ceolotto G, Caroccia B, et al. Genetic screening in arterial hypertension. Nat Rev Endocrinol. 2017; 13(5): 289-298, doi: 10.1038/nrendo.2016.196, indexed in Pubmed: 28059156.

33. Padmanabhan S, Newton-Cheh C, Dominiczak AF. Genetic basis of blood pressure and hypertension. Trends Genet. 2012; 28(8): 397-408, doi: 10.1016/j.tig.2012.04.001, indexed in Pubmed: 22622230 .

34. Jarosz M, Wolańska D, Stolińska H, et al. Nutrition and lifestyle in patients pharmacologically treated due to hypertensionally treated due to hypertension. Cardiol J. 2016; 23(5): 491-496, doi: 10.5603/CJ.a2016.0049, indexed in Pubmed: 27439369.

35. Małyszko J, Tomaszuk-Kazberuk A, Dobrzycki K, et al. Vitamin $\mathrm{D}$ deficiency and anemia is highly prevalent and dependent on the etiology of heart failure: A pilot study. Cardiol J. 2019 [Epub ahead of print], doi: 10.5603/CJ.a2019.0003, indexed in Pubmed: 30697681.

36. Burrello J, Monticone S, Buffolo F, et al. Is There a Role for Genomics in the Management of Hypertension? Int J Mol Sci. 2017; 18(6), doi: 10.3390/ijms18061131, indexed in Pubmed: 28587112 .

37. Wain LV, Vaez A, Jansen R, et al. Novel blood pressure locus and gene discovery using genome-wide association study and expression data sets from blood and the kidney. Hypertension. 2017 [Epub ahead of print], doi: 10.1161/HYPERTENSIONAHA.117.09438, indexed in Pubmed: 28739976.

38. Oren A, Vos LE, Uiterwaal CS, et al. Cardiovascular risk factors and increased carotid intima-media thickness in healthy young adults: the Atherosclerosis Risk in Young Adults (ARYA) Study. Arch Intern Med. 2003; 163(15): 1787-1792, doi: 10.1001/ archinte.163.15.1787, indexed in Pubmed: 12912713.

39. Sacco RL, Blanton SH, Slifer S, et al. Heritability and linkage analysis for carotid intima-media thickness: the family study of stroke risk and carotid atherosclerosis. Stroke. 2009; 40(7): 2307-2312, doi: 10.1161/STROKEAHA.109.554121, indexed in Pubmed: 19498180.

40. Cecelja M, Jiang B, Keehn L, et al. Arterial stiffening is a heritable trait associated with arterial dilation but not wall thickening: a longitudinal study in the twins UK cohort. Eur Heart J. 2018; 39(24): 2282-2288, doi: 10.1093/eurheartj/ehy165, indexed in Pubmed: 29590330. 